\title{
On time differences in searching for letters in words and nonwords: Do they emerge during the initial encoding or the subsequent scan?
}

\author{
NEAL F. JOHNSON and MARY JO CARNOT \\ The Ohio State University, Columbus, Ohio
}

\begin{abstract}
Krueger (1970a, 1970b, 1982) has demonstrated that subjects can search for target letters within words faster than they can complete an equivalent search through nonwords, and he further demonstrated that the effect did not arise during the comparison stage. The present study involved three experiments in which the usual word advantage disappeared either when subjects knew where within a display the target item would appear (i.e., it was always the first letter), or when all the component letters were encoded into memory before the task began (i.e., a memory-search task). These data, in conjunction with Krueger's, where interpreted as localizing at least one (and possibly the only) source of the word-nonword difference in this task to the events that occur during the item-to-item transitions subjects make when scanning the letter arrays. That is, these transitions are faster for words than nonwords, and it was suggested that the time difference may emerge because although all the letters from within a word appear to be available in memory before the scan begins, this seems not to be true for consonant arrays. Given that this is the case, part of the word-nonword difference may be attributable to subsequent encoding events that would be needed for the consonant arrays as the scan moves from letter to letter
\end{abstract}

Krueger (1970a, 1970b, 1982), among others, has reported that if subjects are given words and asked to search for a target letter, their search rates are faster than they are when the letter arrays to be searched are nonwords. In addition, this effect seems to occur regardless of whether the task consists of a visual search or a simultaneous comparison, or whether the task involves presenting a single to-be-scanned array or multiple arrays on each trial (i.e., a Neisser-type task; see Barron \& Pittenger, 1974; Johnson, 1986; Krueger \& Shapiro, 1980; McNamara, Ward, \& Juola, 1978).

The specific issue examined in this study concerns the exact source of the foregoing word-nonword difference, as well as the extent to which data from this task can be used as a basis for drawing conclusions regarding the way we recognize words and read texts. As is suggested above, this is clearly an empirical problem, rather than a theoretical issue. However, the series of hypotheses examined in these experiments was generated on the basis of the implications of a general class of models, which assume that the first available encoding for words tends to be a holistic representation, whereas the first available representation for nonword consonant arrays will likely be in terms of individual letters (e.g., see Drewnowski \& Healy, 1977; Healy \& Drewnowski, 1983; Healy,

Correspondence may be addressed to Neal F. Johnson. Department of Psychology, 404C East Stadium, The Ohio State University, Columbus, $\mathrm{OH} 43210$

- Accepted by previous editor, Alice F. Healy
Oliver, \& McNamara, 1987; Johnson, 1975, 1977, 1981. 1986).

Although the data do indicate that the processing of words is faster than the processing of nonwords in these types of task, it also needs to be noted that the task itself imposes a type of component scan that might not be typical of the ways in which words are usually handled. Furthermore, it is not impossible that the difference in scan rate reported by these investigators may have emerged as a result of these additional and atypical processing events. That is, much of the time that it takes to identify a letter from within a word may involve processing steps and events that occur only after the word itself has been identified, and it is possible that they would not occur at all if the experimental task did not demand such a scan. If this is the case, then the time to identify or detect a letter from within a word cannot be used as an index of what occurs when subjects process a word as a word.

\section{A Preliminary Analysis of the Task}

First, it seems possible to make a crude division between the processing stages and events that are needed to establish or encode an initial representation with which to begin the search-and-comparison process required by letter-search tasks such as those described above, and the subsequent processing stages and events (which could include additional encoding) needed to complete the task. Clearly, within this type of distinction, the steps included within the category of initial processing, as well as those included within the category of subsequent processing, 
should vary, depending on both the nature of the task and the characteristics of the materials.

For example, if subjects need to make a letter-to-letter comparison, as in the above tasks, initial processing will include the processing steps needed to obtain a representation of at least one letter, regardless of whether the display consists of a word or a nonword. However, though the nature of the needed representation may be the same for words and nonwords, the processing steps required to obtain that initial encoding may not be the same for the two types of display. Furthermore, if subjects are to determine whether a word matches a predesignated target word, the type of processing that will be included within the category of initial processing may be quite different than would be the case if the subject's task were to detect whether a letter from within the word matched a predesignated target.

Finally, if subjects detect matches between displayed words and predesignated word targets by comparing word-level codes directly, but detect matches for consonant arrays by making a series of letter-level comparisons (Johnson, Turner-Lyga, \& Pettegrew, 1986), then the needed initial processing will differ, depending on whether the arrays constitute words or nonwords. For words, the initial processing will include everything up to obtaining a word-level code, but for the consonant array, it will include everything up to the point at which the subject has the first letter-level encoding that will allow a letter-to-letter comparison.

Initial processing, then, as it is defined here, includes everything needed to make the first comparison required by the demands of the task, and the nature of this processing will vary as a function of both the task demands and the characteristics of the materials. The term initial encoding refers to the product of that initial processing. Subsequent processing, on the other hand, consists of any additional steps needed to completely fulfill all the demands of the task, and these also will vary from task to task.

With regard to the specifics of the current issue, it may be that the time needed for initial processing is the same for words as it is for nonwords, with the variation in time required by the overall task stemming entirely from encoding, scan, comparison, and decision events that occur subsequently. Furthermore, it could also be the case that while the times needed for the initial processing might be the same for words and consonant arrays, the specific natures of those processing events might be very different.

\section{The Nature of Encoding and \\ Its Relations to Display Characteristics}

In terms of this distinction between initial and subsequent processing, one reason that such a suggestion is interesting is that it is possible that words constitute visual patterns that are always encoded holistically, with the holistic representation being the basis for word identification. On the other hand, models that make such an assumption also assume that letter patterns that cannot be unitized readily (e.g., consonant arrays) are encoded on a letter-by-letter basis (Drewnowski \& Healy, 1977; Healy \& Drewnowski, 1983; Johnson, 1977, 1981; Johnson et al., 1986; Johnston \& McClelland, 1980), with no unitary pattern-level representation being involved.

Therefore, such a model would imply that although the first available encoding for words would be a unitized representation of the word itself, the first available encoding for a consonant array would be for one of the individual letters. For a consonant array, the first available encoding would also be what is defined here as the initial encoding, which would be true regardless of whether the subject's task was to identify the entire pattern or just a letter within the array. For words, on the other hand, the first available encoding would be a holistic representation of the entire word, which would be the initial encoding only if subjects were to identify the word. If their task was to identify a letter from within the word, then additional processing would be required in order to derive the initial letter-level encoding from the word code.

In this context, holistic encoding can be defined as encoding instances in which pattern-level representations (in this case, word-level codes) are more immediately available to cognitive processing mechanisms than are comparable codes for the components of the array, and the data that illustrate the effect consist of demonstrations that subjects can report that a display such as BLOCK matches a predesignated target word block more quickly than they can report that the display begins with the predesignated target letter $B$ (Johnson, 1975). On the other hand, if the display is a consonant array, for which holistic processing should not be possible, just the reverse seems to be the case (Johnson et al., 1986). This empirical distinction makes such an operational definition useful.

\section{A Processing Model}

In terms of the model, it would be assumed that the first attempts at encoding a visual array or pattern always are holistic, and that although these attempts would succeed if the display was a word, they would fail with equal certainty in the case of a consonant array. In the latter situation, the perceiver would then have to parse the display and encode it serially on a letter-by-letter basis. Furthermore, such a failure at holistic encoding would be the only basis for the perceiver's knowing that the display could not be unitized. As has been stated above, this assumption fits most closely with the specifics of the pattern-unit model (Johnson, 1977, 1981, 1986), but the unitization model (Drewnowski \& Healy, 1977; Healy, Oliver, \& McNamara, 1987) and the Johnston and McClelland (1980) model (as well as some others) would make the same general predictions in the context of the following experiments.

An interesting implication of the foregoing construction of the issue is that if word processing is always holistic, then, whenever one looks at a word, the only cognitive representation that will become available will be the word-level code. If the perceiver then should look at the display again, in an effort to see the letters, the resulting 
holistic encoding event would once again provide a wordlevel code, but no letter codes. The problem, then, is that this type of view does not allow for any direct encoding of letter information from an array if the array forms a word.

In order to account for the fact that we obviously can "see" the letters from within words (at least in some sense), models of this type would need to assume that we decode the word-level code within memory, and in that way derive the letter information from the word-level code without directly encoding the letter information from the display itself. However, codes seem to be opaque, and it appears that all the information they represent becomes immediately available when they are decoded (Johnson, 1970). If this is the case, whenever we have any representation of a letter from a word available in memory for purposes of comparing it with a predesignated target, the decoding process should also have made available memorial representations of all the other letters as well (i.e., it is not possible to selectively encode the letters from within a word into memory). (See Johnson, 1986, for a more detailed presentation and documentation of these points.)

For displays that cannot be unitized, the situation would be somewhat different. Since it is assumed that consonant arrays are not encoded holistically, but rather on a letterby-letter basis, then when the first letter from the array is available in memory for comparison with the target (i.e., initial processing is complete), there is no reason to believe that any of the other letters would also have been encoded into memory at that point in time. If the first encoded letter did not match the target, then further letter encoding would be required in order to determine whether any other letter in the display matched the target, and that subsequent encoding should delay the response even further. (Again, see Johnson, 1986, for a more detailed presentation of this issue, as well as empirical documentations of the expected effects.)

\section{The Current Issue}

With regard to the task involved in the type of wordnonword effect reported by Krueger (1970a, 1970b, 1982), the foregoing model predicts that there could be differences in the time required for the initial processing events in the two situations, because it is assumed that the natures of these events are quite different, depending on the type of display. In addition, there is now rather clear evidence for the reality of these expected differences in the nature of the initial encoding and processing events for word and nonword letter arrays (Johnson, 1986; Johnson et al., 1986).

Although the reality of these differences in the nature of the processing seems to be unambiguous, there would be no basis within the framework of the pattern-unit model (Johnson, 1977, 1981) for any particular prediction one way or the other regarding which of the two tasks (consonants vs. words) should yield the quickest initial encoding (whether there might be a prediction is less clear for the other models of this type). However, most im- portantly, the available data (Sloboda, 1976, 1977) indicate that in fact there is no reaction time difference between the two tasks when only the initial processing events are required by the task (see also Johnson, 1986, for additional data on this point). Since the nature of the initial encoding seems to be so different for these two types of display, the equivalence in time for those events to occur must be considered a coincidence.

The model predicts that, once the initial processing or encoding is complete, there should also be differences in the nature of the subsequent processing events for words and consonant arrays if further scanning and comparison events are required by the task (e.g., as would be true if the target letter could appear anywhere within the display, and all letter positions would have to be searched). Specifically, in the case of a word, if the word had been encoded holistically, and the letter information had then been derived from that code within memory, all of the needed memorial encoding of the letter information would have been completed before the scan began. In that case, if the task was to detect the presence or absence of some specific letter within the display, just a simple fast memory scan (Sternberg, 1966) involving the needed comparisons and decision(s) should do the job.

On the other hand, if the display was a nonunitizable consonant array, and such subsequent processing was needed, the task should be much more complicated. In particular, the product of the initial processing would be a cognitive representation of only a single letter (most likely the first letter, but not necessarily). Any subsequent scanning of the other items in the array would then entail a cognitive encoding of each item as a first step before any comparisons and decisions could be made. A fast memory scan therefore could not occur, because each item-to-item transition within the scan would involve an encoding event as well as a comparison and possibly (probably?) a decision. The cognitive encoding event would retard the rate of scan in comparison with what would occur had the display been a word and all cognitive encoding had been completed before the scan began.

If the subject's task in an experimental paradigm was to identify the letter in a specific position within a word or consonant array, there would be no need for a scan, and the product of the initial processing or encoding could be used for the task. The model, combined with existing data, would lead to the prediction that a subject's decision latency would not be influenced by whether the display consisted of a word or a consonant array. However, if the predesignated target letter could appear anywhere in the display, and a scan was needed, the extra encoding event at each transition within the scan required by a consonant array would make the scan noticeably slower than would be the case had the display been a word.

\section{EXPERIMENT 1}

The displays in Experiment 1 consisted of either sixletter words or arrays of six consonants. The subjects' task in one condition was to determine whether the first 
letter of the display matched a predesignated target; in another condition, the target letter could appear in any letter position, and the subjects were to scan the entire array. It was expected from the foregoing scanning hypothesis regarding the word-nonword difference that although a word advantage might be obtained for the latter condition, the effect would be eliminated if the subjects knew where to focus their attention.

\section{Method}

The six-letter displays were typed in IBM Orator lowercase type, which are really just small capital letters. IBM Orator is a 10-point type, but the displays were typed on a 12-point typewriter, so single spaces were left between the letters in order to avoid crowding. At the 31-in. viewing distance, the displays were seen as capital letters appropriately spaced. The visual angle of each display was $1.7 .^{\circ}$

The displays were presented in blocks of 18 , and each subject saw 12 blocks. Within a block, the items were either all words or all consonant strings, and a different predesignated target letter (always a consonant) was used for each display. In addition, the consonant strings were constructed by replacing all the vowels of a word display with consonants, which resulted in each block of word displays having a corresponding block of consonant displays. However, two sets of materials were used, and for any subject the words from one set were always paired with the consonant displays constructed from the other word set, and vice versa.

For each display, the first letter was the critical item when the display appeared in the condition in which subjects were to confine their search to the very first letter position, and this resulted in each of the 18 displays in a block beginning with a different consonant. In addition, a second consonant in each display was designated as the critical item for when that display was to appear in the condition in which the target could appear in any letter position. Within a block, the critical consonant appeared in each of the six letter positions for 3 displays each, and 18 different consonants were used as the critical items.

Each subject received all six blocks of displays involved in one type of search (i.e., first position vs. any position) before receiving the six blocks for the other type of search, and within one type of search task, the subjects were presented with all the word displays before the consonant displays, or vice versa. Before each block of displays was presented, both the nature of the displays and the type of search required were described to the subjects.

For each type of display (i.e., words vs. consonants) each block appeared in each type of search task for an equal number of subjects, and within a search task, the order of the three blocks of each type was random. In addition, within a block, the predesignated target for a display was the critical item for one half of the displays (YES items), and the target was a letter that did not appear in the display for the other half (NO or foil items). However, across subjects, each display appeared as a YES and as a NO item for an equal number of subjects.

Finally, to increase the sample of materials in the experiment, two different sets of materials were used, and when that was counterbalanced with all of the foregoing, the result was counterbalancing cycles of 16 subjects, and one such cycle was used. The 16 subjects were undergraduate students at Ohio State who participated as part of a course option.

Each display was presented for $1 \mathrm{sec}$. Immediately before each item appeared, the subjects attended to a central fixation point, and they were told which letter would be the target for that display. This was followed by the experimenter's saying "ready," and the display then appeared approximately 500 msec later, with the subjects responding YES or NO by pressing one of two buttons (the subjects chose which hands they wanted to use for YES and NO).
For the analysis of the latency data, only the latencies for correct responses were included.

The display apparatus was a Scientific Prototype two-channel tachistoscope (Model 800E), and the stimulus that triggered the display also started the timer, with the buttonpress turning off the timer. The displays were presented at a rate of approximately one every $10 \mathrm{sec}$, and the subjects were given a short rest between blocks.

\section{Results}

The error results of the experiment are presented in Table 1 (the mean error rate was $2.4 \%$ ). An analysis of the error data indicated a reliable effect for search condition $\left[F(1,15)=6.71, M S_{\mathrm{e}}=5.75, p<.05\right]$ with the subjects making more errors when they did not know the position of the target $(2.95 \%$ vs. $1.85 \%)$. However, this difference was positively correlated with latency, and none of the other effects or interactions were reliable, with the largest difference being for type of response $[F(1,15)=$ $\left.2.29, M S_{\mathrm{e}}=5.64, p>.05\right]$.

A comparable analysis of the latency results, which are reported in Table 2 (correct responses only), indicated that the time to respond was faster when the subjects knew the location of the target $\left[F(1,15)=101.70, M S_{\mathrm{e}}=\right.$ $.0166, p<.001]$; when the displays were words $\left[F(1,15)=8.99, M S_{\mathrm{e}}=.0094, p<.01\right] ;$ and that a

Table 1

Mean Percentage of Errors for Each Condition in Experiment 1

\begin{tabular}{lccc}
\hline & \multicolumn{3}{c}{ Type of Search } \\
\cline { 2 - 4 } Response Type & First Position & Any Position & Mean \\
\hline \multicolumn{2}{c}{ Words } \\
Yes & 1.62 & 3.01 & \\
No & 1.85 & 2.78 & 2.32 \\
Mean & 1.73 & 2.90 & 2.32 \\
& Consonants & & \\
Yes & 2.78 & 3.47 & 3.13 \\
No & 1.16 & 2.54 & 1.85 \\
Mean & 1.97 & 3.01 & 2.49 \\
& Both Displays & \\
Yes & 2.20 & 3.24 & 2.72 \\
No & 1.50 & 2.66 & 2.08 \\
Mean & 1.85 & 2.95 & 2.46 \\
\hline
\end{tabular}

Table 2

Mean Latency in Milliseconds for Each Condition in Experiment 1

\begin{tabular}{lccc}
\hline & \multicolumn{3}{c}{ Type of Search } \\
\cline { 2 - 4 } Response Type & First Position & Any Position & Mean \\
\hline \multicolumn{3}{c}{ Words } & \\
Yes & 602 & 814 & 708 \\
No & 682 & 866 & 774 \\
Mean & 642 & 840 & 741 \\
\multicolumn{3}{c}{ Consonants } \\
Yes & 640 & 861 & \\
No & 682 & 985 & 751 \\
Mean & 661 & 923 & 834 \\
& Both Displays & 792 \\
Yes & 621 & 838 & \\
No & 682 & 926 & 829 \\
Mean & 652 & 881 & 766 \\
\hline
\end{tabular}


YES response was faster than a NO $[F(1,15)=75.42$, $\left.M S_{\mathrm{e}}=.0024, p<.001\right]$. In addition, the expected interaction between type of display and type of search task was obtained $\left[F(1,15)=5.07, M S_{\mathrm{e}}=.0064, p<.05\right]$, with the effect of display type being substantially larger for the condition in which the subjects did not know the location of the target as opposed to when they did know. Finally, there was a reliable conditions $\times$ display type $\times$ response type interaction $\left[F(1,15)=17.91, M S_{\mathrm{e}}=\right.$ $.0014, p<.001]$.

Although there was a rather large advantage of $83 \mathrm{msec}$ for word displays over consonant arrays when the subjects did not know where to focus their attention $[F(1,15)=$ $\left.9.82, M S_{\mathrm{e}}=.0113, p<.05\right]$, and only three of the subjects failed to show the effect, a separate analysis of the results from the condition in which the subjects were told to focus their attention on the first letter indicated that the effect of display type was not significant $[F(1,15)=$ $\left.1.32, M S_{\mathrm{e}}=.0045, p>.05\right]$. There was, however, an effect of response type (YES vs. NO) $[F(1,15)=43.42$, $\left.M S_{\mathrm{e}}=.0014, p<.001\right]$, as well as an interaction between response type and display type $[F(1,15)=11.18$, $\left.M S_{\mathrm{e}}=.0005, p<.01\right]$. The interaction seems to have emerged because of an effect of display type on the YES responses $\left[F(1,15)=5.48, M S_{\mathrm{e}}=.0022, p<.05\right]$, with the latency being somewhat longer for the consonants.

\section{Discussion}

The purpose of Experiment 1 was to determine whether the fact that subjects can find letters in words faster than in nonwords should be attributable to the time needed to establish what has been defined here as the initial encoding, or to events that occur when subjects scan the encoding. The results indicated that while the usual word-nonword effect was obtained, with subjects handling the words more rapidly than the nonwords, the effect interacted with the type of search task. That is, there was no reliable word-nonword difference when the subjects knew in advance where to focus their attention. This result suggests that, to a large degree, the word-nonword difference reported by Krueger (1970a, 1970b, 1982) may have resulted from a difference in the time needed to scan words as opposed to nonwords, rather than a difference in the time needed for their initial encoding. (However, again it should be noted that the scan itself might involve additional encoding events, particularly in the case of consonant arrays.)

The one problem that adds ambiguity to the data is that for the task in which subjects knew where to focus their attention, there was an interaction between response and display type. Even though the overall difference between words and nonwords was not significant, there did appear to be a slight effect of display type on the YES response. What makes this outcome perplexing, however, is that the same condition in the prior study (Johnson, 1986) did not show such an effect, with all the main effects and interactions yielding $F$ s of less than 1 . Furthermore, in a pilot study that replicated the present experiment exactly (in which, it should perhaps be mentioned, the experimenter was inexperienced and tested the subjects solely for the purpose of getting experience with the equipment), there also was no interaction between response and display type for this task, and for neither response type was there any advantage for the word displays. In all other respects, however, the data from the two studies were essentially identical.

\section{EXPERIMENT 2}

The purpose of Experiment 2 was to examine again the effect of word as opposed to nonword displays when subjects attempted to determine whether the first letter of a display matched a predesignated target. The interaction obtained in Experiment 1 between response and display type raised a question regarding the interpretation of those data, and the specific issue in Experiment 2 concerned whether that effect would be replicated.

\section{Method}

The procedure and display materials for Experiment 2 were identical to those for Experiment 1, with the exception that the subjects were always to focus on the first letter of the display. Each subject received 12 blocks of 18 displays, 6 of them words and 6 of them consonant arrays, and the subjects always saw the 6 blocks of one type of display before the 6 from the other.

Again, the subjects were 16 undergraduate students who participated as part of a course option. Although the number of subjects was the same as in Experiment 1, the number of observations per subject per condition was doubled in Experiment 2, because only the task in which the target always appeared in the initial position was used, which should have resulted in a favorable increase in the reliability of the data.

\section{Results and Discussion}

The error data from Experiment 2 are presented in Table 3 (the mean error rate was $2.9 \%$ ). An analysis of the error data indicated that none of the effects were reliable. The effect for response type (YES vs. NO) was the largest $\left[F(1,15)=4.13, M S_{\mathrm{e}}=2.91, p>.05\right]$, with the effects for display type $\left[F(1,15)=1.35, M S_{\mathrm{e}}=3.19\right.$, $p>.05]$ and the interaction $\left[F<1.00, M S_{\mathrm{e}}=7.11\right]$ being considerably smaller.

An analysis of the latency data reported in Table 4 (correct responses only) indicated that although the usual advantage for YES responses was obtained $[F(1,15)=$ $\left.17.34, M S_{\mathrm{e}}=.0026, p<.001\right]$, neither the effect of display type $\left[F<1.00, M S_{\mathrm{e}}=.0104\right]$ nor the interaction $\left[F<1.00, M S_{\mathrm{e}}=.0010\right]$ was reliable. Consistent with the prior study, as well as the pilot experiment for Experiment 1 , this experiment indicates no reliable difference between words and nowords when subjects are to

Table 3

Mean Percentage of Errors for Each Condition in Experiment 2

\begin{tabular}{cccc}
\hline & \multicolumn{3}{c}{ Display Type } \\
\cline { 2 - 4 } Response Type & Word & Consonants & Mean \\
\hline Yes & 3.12 & 3.47 & 3.30 \\
No & 2.08 & 2.78 & 2.43 \\
Mean & 2.60 & 3.12 & 2.86 \\
\hline
\end{tabular}


Table 4

Mean Latency in Milliseconds for Each Condition in Experiment 2

\begin{tabular}{cccc} 
& \multicolumn{3}{c}{ Display Type } \\
\cline { 2 - 4 } Response Type & Word & Consonants & Mean \\
\hline Yes & 619 & 625 & 622 \\
No & 674 & 676 & 675 \\
Mean & 646 & 651 & 649 \\
\hline
\end{tabular}

determine whether the display's first letter conforms to a predesignated target.

\section{EXPERIMENT 3}

The results thus far indicate that there is no demonstrable influence of a word-nonword difference on what has been defined here as initial processing or encoding. However, when the experimental task demands subsequent processing, then there is a clear word-nonword difference. In initial processing, as was predicted, the data indicate (Johnson, 1975; Johnson et al., 1986), that in the case of a word, the first immediately available cognitive representation is a word-level encoding that can be decoded within memory into all the component-letter information. On the other hand, in the case of a consonant array, it is equally clear that the initial encoding does not involve a pattern-level representation, but rather a specific piece of component-level information (e.g., a letter) (Johnson et al., 1986).

Given these considerations, if subjects must scan and consider all the items in the array, as would be the case if the subjects were to determine whether any item in the array matched the predesignated target, then after the initial processing was complete, subsequent processing would be required. In the case of a word, the initial processing would provide a memorial encoding for all of the component letter information. This should mean that in the scan-and-comparison process all that would be needed is a rapid shift in attention from one memorial code to another (i.e., a fast memory scan).

On the other hand, for a consonant array, when a subject is to make a transition to the next item within the scan, there should be no preexisting memorial code available for that next item, and therefore the subject must go through an encoding process to provide one. In addition, the self-terminating scan suggests that subjects also make a decision regarding the prior item at that point. The extra encoding and decision events at each transition within the scan should be the only processing differences between what occurs when the letter array forms a word and when it is a consonant array; and the need for these processing events should account for part, if not all, of the difference in scan rate between the two types of display.

This issue was explored in Experiment 3, by means of comparing scan rates when the need for transitional encoding and decision events for the consonants was eliminated, simply by shifting from a visual-scan to a memoryscan task (Sternberg, 1966). The subjects were shown the letter array in advance, and then it was removed from view. They were then shown a single probe letter, and their task was to determine whether the probe letter had appeared anywhere in the previously seen display.

Given that all of the letter information for both the consonants and the words would be in memory before the scan begins, there would be no need or possibility for any type of subsequent letter encoding for either kind of display. Therefore, to the extent that the word-nonword difference obtained with a visual scan in Experiment 1 is attributable to encoding and decision events during the scan for the consonants, the difference should be reduced or eliminated in Experiment 3.

\section{Method}

The materials were words or consonant arrays that consisted of three or six letters. There were 144 displays of each type, presented in separate blocks of trials. Half the subjects saw all the consonant displays before the word displays, and the reverse was true for the other half of the subjects. In addition, within each type of display, half the subjects had the three-letter items before the six-letter items, with the reverse true for the other half.

There was no attempt to control for word frequency, and the only criterion used for the words was that two undergraduate experimenters agree that they would be familiar to freshman undergraduates. The criterion used for the consonant arrays was that they not be a familiar letter sequence, or, in the case of the six-letter arrays, that they not contain any familiar sequence of consonants. For half the displays of each type, the probe letter was not in the display (i.e., the NO items), but the probe was a member of the letter set for the other half (i.e., the YES items); and across displays the positive probes appeared in each letter position equally often. In addition, across subjects, each letter set was a YES and a NO item for an equal number of subjects, and there were eight different random orders in which the items in the lists were presented.

The apparatus consisted of a Northstar Horizon computer and two Televideo $920 \mathrm{C}$ terminals (white phosphor). One terminal was used by the experimenter to control the flow of the experiment, while the other terminal was the display console and response panel used by the subject. The displays consisted of white characters on a dark background.

For each trial, the display sequence consisted of first presenting the subject with the letter set (either words or consonants) that he or she was to register in memory for the subsequent test. After a short interval during which the subject studied the item and registered it in memory, the experimenter asked, "ready?" - and if the subject did not give a negative reply, the experimenter triggered the remainder of the display sequence.

The sequence consisted of first clearing the computer screen of the letter-set display, which was immediately followed by three rows of either 12 or 13 Xs that covered an area on the screen whose center was the location at which the letter set had appeared ( $\mathrm{X}$ was never used as a probe letter). The $\mathrm{Xs}$ remained on for approximately $350 \mathrm{msec}$, followed by the screen's being cleared, and the probe letter then appeared at the center of where the $\mathrm{X}$ array had been.

The subjects were 24 undergraduate students at Ohio State who participated as part of a course option, and they were instructed to press the ?/-key on the terminal keyboard if the probe did conform to one of the letters in the immediately preceding letter set, and to press the Z-key if the probe did not appear in that set. In addition, they were told to respond as quickly as possible, consistently with making few if any errors. The latency for $5.5 \%$ of the responses either exceeded $1,500 \mathrm{msec}$ or was less than $300 \mathrm{msec}$, and these responses were not included in the analysis of either the 
Table 5

Mean Percentage of Errors for Each Condition in Experiment 3

\begin{tabular}{|c|c|c|c|}
\hline \multirow[b]{2}{*}{ Response Type } & \multicolumn{2}{|c|}{ Memory-Set Size } & \multirow[b]{2}{*}{ Mean } \\
\hline & Three Letters & Six Letters & \\
\hline \multicolumn{4}{|c|}{ Words } \\
\hline Yes & 4.67 & 6.58 & 5.63 \\
\hline No & 5.71 & 5.33 & 5.52 \\
\hline Mean & 5.19 & 5.96 & 5.57 \\
\hline \multicolumn{4}{|c|}{ Consonants } \\
\hline Yes & 6.25 & 10.79 & 8.52 \\
\hline No & 5.67 & 13.38 & 9.52 \\
\hline Mean & 5.96 & 12.08 & 9.02 \\
\hline \multicolumn{4}{|c|}{ Both Displays } \\
\hline Yes & 5.46 & 8.69 & 7.07 \\
\hline No & 5.69 & 9.35 & 5.52 \\
\hline Mean & 5.57 & 9.02 & 7.30 \\
\hline
\end{tabular}

latency data or the error data (less than $.5 \%$ of the responses from the first two experiments fell outside these limits).

\section{Results}

The overall error rate was $7.3 \%$, and the error data are reported in Table 5. An analysis of the data indicated that the subjects encountered memory problems with the consonant displays $\left[F(1,23)=11.97, M S_{\mathrm{e}}=47.67, p<\right.$ $.01]$ and the six-letter displays $\left[F(1,23)=29.04, M S_{\mathrm{e}}=\right.$ $19.65, p<.01]$. In addition, the length effect was somewhat greater for the consonant displays $[F(1,23)=18.35$, $\left.M S_{\mathrm{e}}=18.74, p<.01\right]$, but the errors for the six-letter words were unusually low, which resulted in a three-way interaction $\left[F(1,23)=13.88, M S_{\mathrm{e}}=6.44, p<.01\right]$.

The latency data are presented in Table 6 . An analysis indicated a reliable effects for display type $[F(1,23)=$ $\left.10.14, M S_{\mathrm{e}}=.0115, p<.001\right]$, size of the letter set to be searched $\left[F(1,23)=91.17, M S_{\mathrm{e}}=.0056, p<.001\right]$, and response type $\left[F(1,23)=84.16, M S_{\mathrm{e}}=.0038\right.$, $p<.0011$. In general, the subjects were slower in responding when the displays were consonants. In addition, it took them longer to respond when the letter sets contained six letters rather than three, suggesting a serial search of the memory set, and the subjects were faster in responding when the probe appeared in the memory set (i.e., YES items).

The interaction between response type and letter-set size was not reliable $\left[F<1.00, M S_{\mathrm{e}}=.0002\right]$, which suggests the type of exhaustive search that is characteristic of memory scans, and this effect did not interact with display type $\left[F<1.00, M S_{e}=.0013\right]$, indicating no basis for suggesting any difference in search strategy correlated with whether the displays consisted of words or consonant arrays. However, most importantly, the interaction between display type and search-set size also was not reliable $\left[F<1.00, M S_{\mathrm{e}}=.0061\right]$, which indicates no detectable difference in search rates between the words and consonant arrays. Finally, an analysis of all the latency data, including those outside the limits of 300 and $1,500 \mathrm{msec}$, resulted in the same pattern of reliabilities, with the most extreme change being for the interaction between display type and length $\left[F(1,23)=2.23, M S_{e}\right.$ $=.0146, p>.05]$.

\section{Discussion}

The critical results in Experiment 3, then, are the demonstration of a marked effect on search time of the size of the array that needed to be searched, while at the same time there was no suggestion that the search rate through the letter set was in any way influenced by the type of array that needed to be searched (i.e., words vs. consonants). Clearly, it is the case that the important outcome was a null effect (i.e., there was no length $x$ display type interaction), and, with regard to the current issues, this does reduce the significance of the experiment in that the data pattern could simply be the result of a reliability problem.

However, with respect to this issue of reliability, the absence of an effect in Experiment 3 can be compared to the marked interaction obtained in Experiment 1, which in fact contained far fewer observations. In addition, Gilford and Juola (1976) had included the conditions that were used in this experiment as a subset of the conditions within their study, and they obtained precisely the same result. Furthermore, in a subset of conditions within the

Table 6

Mean Latency in Milliseconds for Each Condition in Experiment 3

\begin{tabular}{|c|c|c|c|c|}
\hline \multirow[b]{2}{*}{ Response Type } & \multicolumn{4}{|c|}{ Display Length } \\
\hline & Three Letters & Six Letters & Mean Difference & Mean \\
\hline \multicolumn{5}{|c|}{ Consonants } \\
\hline Yes & 686 & 791 & 105 & 738 \\
\hline No & 771 & 884 & 113 & 827 \\
\hline Mean & 728 & 837 & 109 & 783 \\
\hline \multicolumn{5}{|c|}{ Words } \\
\hline Yes & 648 & 745 & 97 & 696 \\
\hline No & 722 & 819 & 97 & 771 \\
\hline Mean & 685 & 792 & 97 & 734 \\
\hline \multicolumn{5}{|c|}{ Overall Mean } \\
\hline Yes & 667 & 768 & 101 & 717 \\
\hline No & 746 & 852 & 106 & 799 \\
\hline Mean & 707 & 810 & 103 & 758 \\
\hline
\end{tabular}


McNamara, Ward, and Juola (1978) experiment, as well as in Johnson (1986), when subjects were required to engage in a visual scan, which should have entailed the predicted type of transitional encoding events for the consonants, there were very marked interactions between display type and the size of the search set.

Overall, then, it does appear that if the task does not force subjects to encode all the items from an array into memory before beginning the search, they are slower if the array contains just consonants than if it is a word. However, this differential scan rate all but disappears (in fact, it may disappear) when the task requires all the items to be in memory before the scan begins. The pattern of data would seem to be quite consistent with the view that at least one source of the difference in scan rate for the visual-scan task consists of the transitional encoding and decision events that occur during the scan of consonants but not words.

One important result of Experiment 3 that is not wholly consistent with expectations was the reliable overall latency advantage for the words. Gilford and Juola (1976) also reported such a word advantage. Since this difference was an intercept effect, rather than a slope effect, and since it did not interact with any other factor, it appears to stem from some processing event that occurred before the scan began or after it was completed. However, the data from Experiment 1 suggest that initial processing also is not influenced by display type. Therefore, a preliminary suggestion would be that the main effect for display type obtained in Experiment 3 reflects processing events that occur after initial processing is complete, but before the scan has begun. The possibility of its occurring during the decision, response selection, or execution stages seems unlikely. In addition, if it did occur at one of those points, it also should have been obtained when the target was always in the first position.

\section{GENERAL DISCUSSION}

These three experiments have been focused on the question of why subjects can detect predesignated target letters more rapidly when they appear in a word context than when the target letters appear in a nonword context. Krueger's (1970a, 1970b, 1982) original finding suggests that whatever the source of this effect, it is probably not completely under the volitional control of the subjects, because it seems to occur regardless of whether subjects know the nature of a display in advance.

In addition, Krueger's (1970a, 1982) data suggest also that it is probably not a comparison-stage phenomenon, because, when he varied the number of comparisons that the subjects would have to make by varying the number of predesignated target letters, there was no variation in the magnitude of the word-nonword difference. On the basis of such results, Krueger concluded that the difference probably arose during the initial encoding of the item.

Typically, Krueger has viewed the scan that must precede the comparison events in a task such as this as belonging to the encoding stage (personal communication,
1988). What is being suggested here, however, is that we might draw a distinction between the events that are involved in establishing an initial representation and the events that are involved with the scanning and comparison stages that occur later (again, note that scanning may entail some supplementary encoding in the case of consonant arrays). In this context, the hypothesis is that the time differences obtained when subjects scan words as opposed to nonwords may not arise during the initial or preliminary perceptual encoding of the array, but rather when subjects attempt to scan the display in order to make the requisite comparisons with the target.

The data from Experiment 1 thus indicate that when subjects need to scan the display and make multiple comparisons, a large word-nonword difference appears, but this effect disappears when the need for a scan and multiple comparisons is eliminated through telling the subjects where to focus their attention. This suggests that the effect arises sometime after the initial encoding is complete during the scan and comparison events.

As noted above, Krueger (1970a, 1982) varied the number of comparisons that were needed, and the fact that the word-nonword difference did not change in this situation was interpreted as indicating that the comparison stage or stages were not involved (i.e., increasing the number of needed comparisons did not magnify the effect). This point is also supported by the present data to the extent that even when the subjects knew where to focus their attention, one comparison was needed by them in order to respond, and if the comparison step is more difficult for a nonword than for a word display, there should have been a word-nonword difference in this situation. But there was not. In general, then, the comparison event itself seems not to be the source of the effect.

In addition, it is also interesting that, although Krueger did vary the number of comparisons, he did so by increasing the number of targets for which the subject was to search, rather than by increasing the size of the display to be scanned. Thus, although he did increase the number of needed comparisons, he did not increase the number of item-to-item transitional events during the scan, and therefore it is only the comparison events, not the scan itself, that was eliminated from consideration by the data.

Similarly, in the first two experiments of the present study, the need for a scan was eliminated, while the initial encoding and final comparison events were still required, and under these circumstances there again did not appear to be any word-nonword difference. On the other hand, in experiments in which the number of comparisons is increased by increasing the size of the display, the influence of display size does seem to interact with the word-nonword difference (Johnson, 1986, Johnson, Pugh, \& Blum, 1989; McNamara et al., 1978). (See also Krueger \& Shapiro, 1980, for a general review of this work.)

When these pieces of information are combined, the resulting picture seems to suggest that the item-to-item transitional events during the scan might be the source 
of the latency difference obtained when subjects scan words and nonwords for target letters. Specifically, the general type of model that was used to guide the present series of experiments suggests that one important difference between scanning words and scanning consonant arrays should be the encoding and decision events needed at the transitions for the consonant arrays.

Experiment 3 was designed to explore that issue, by ensuring that no transitional encoding and decision events would be needed for the consonants-which, according to the current view, should eliminate (or at least reduce) the difference in within-display scan rate between wordand consonant-array displays. This was accomplished by requiring that the consonants be registered in memory in advance, and not allowing any type of visual search by removing the display before the onset of the probe.

Under these circumstances, the difference in scan rate between the two types of display did in fact disappear. The final conclusion for this series of experiments is that a large portion of the difference in scan rate for words and consonant arrays is attributable to the fact that all the letters from words appear to be in memory before the scan begins, yet for consonant arrays not only do subjects make decisions at each transition during the scan, but the letters are encoded into memory on a letter-by-letter basis as the scan progresses. Such a conclusion is quite consistent with holistic models of word recognition, which assume that words are encoded into memory as units, whereas nonunitizable arrays such as consonant strings are processed at the component level.

Finally, with regard to whether the scanning task is useful for studying word perception, these data, coupled with those reported earlier (Johnson et al., 1986), suggest that performance in tasks of this sort is heavily influenced by processing events that occur only after the word has been encoded in such a way that it can be identified. In addition, it is probably the case that these processing events occur only in tasks such as these, which specifically require the use of component-letter information, and that they do not occur when the task demands only word identification. Obviously, if one subscribed to a letter-integration view of word recognition like that of Gough (1972) or like Mewhort's scanning model (Mewhort, 1974; Mewhort \& Beal, 1977), then a task of this sort would be directly related to one of the assumed stages in reading. The problem is that there is little or no empirical documentation for the reality of such stages, and until such documentation is available, the current data suggest that tasks that force these stages may not reflect what occurs during normal reading.

\section{REFERENCES}

Barron, R. W., Pittenger, J. B. (1974). The effect of orthographic structure and lexical meaning on same-different judgements. Quarterly Joumal of Experimental Psychology, 26, 566-581.

DreWNowski, A., Healy, A. F. (1977). Detection errors on the and and: Evidence for reading units larger than the word. Memory \& Cognition, 5, 636-647.
Gilford, R. M., \& JUOLA, J. F. (1976). Familiarity effects on memory search and visual search. Bulletin of the Psychonomic Society, 7 , $142-144$

GovGH, P. B. (1972). One second of reading. In J. Kavanagh \& I. Mattingly (Eds.), Language by ear and by eye (pp. 331-358). Cambridge. MA: MIT Press.

Healy, A. F., \& Drewnowski, A. (1983). Investigating the boundaries of reading units: Letter detection in misspelled words. Joumal of Experimental Psychology: Human Perception \& Performance, 9. 413-426.

Healy, A. F., Oliver, W. L., \& McNamera, T. P. (1987). Detecting letters in continuous text: Effects of display size. Journal of Experimental Psychology: Human Perception \& Performance, 13, 279.290

Johnson, N. F. (1970). The role of chunking and organization in the process of recall. In G. Bower, (Ed.), Psychology of learning and motivation: Advances in research and theory (Vol. 4, pp. 171-247). New York: Academic Press.

JoHNSON, N. F. (1975). On the function of letters in word identification: Some data and a preliminary model. Joumal of Verbal Leaming \& Verbal Behavior, 14, 17-29.

JOHNSON, N. F. (1977). A pattern-unit model of word identification. In D. LaBerge \& S. J. Samuels (Eds.), Basic processes in reading: Perception and comprehension (pp. 91-126). Hillsdale, NJ: Erlbaum.

JohNSON, N. F. (1981). Integration processes in word recognition. In O. Tzeng \& H. Singer (Eds.), Perception of print: Reading research in experimental psychology (pp. 29-64). Hillsdale, NJ: Erlbaum.

JoHNSON, N. F. (1986). On looking at letters within words: Do we "see" them in memory? Journal of Memory \& Language, 25, 558-570.

Johnson, N. F., Pugh, K. R., Blum, A. J. (1989). More on the way we "see" letters from words within memory. Joumal of Memory \& Language, 28, 155-163

Johnson, N. F., Turner-Lyga, M. , Pettegrew, B. S. (1986). Partwhole relationships in the processing of small visual patterns. Memory \& Cognition, 14, 5-16

Johnston, J. C., \& MCClelland, J. L. (1980). Experimental tests of a model of word identification. Joumal of Verbal Leaming \& Verbal Behavior, 19, 503-524

Krueger, L. E. (1970a). Search time in a redundant visual display. Journal of Experimental Psychology, 83, 391-399.

KRUEGER, L. E. (1970b). Visual comparison in a redundant display. Cognitive Psychology, 1, 341-357.

KRUEGER, L. E. (1982). A word-superiority effect with print and braille characters. Perception \& Psychophysics, 31, 345-352.

Krueger, L. E. , Shapiro, R. G. (1980). Why search for target absence is so slow (and careful!): The more targets there are the more likely you are to miss one. Joumal of Experimental Psychology: Human Perception \& Performance, 6, 662-685.

MCNamara, T., Ward, N., Juola, J. F. (1978). Visual search for letters in intact and mixed-case words and nonwords. Bulletin of the Psychonomic Society, 12, 297-300.

MEwhoRT, D. J. K. (1974). Accuracy and order of report in tachistoscopic identification. Canadian Joumal of Psychology, 28, 383-398.

MEwhort, D. J. K., \& BeAL, A. L. (1977). Mechanisms of word identification. Journal of Experimental Psychology: Human Perception \& Performance, 3, 629-640.

Sloboda, J. A. (1976). Decision times for word and letter search: A wholistic word identification model examined. Joumal of Verbal Learning \& Verbal Behavior, 15, 93-101.

SLOBODA, J. A. (1977). The locus of the word-priority effect in a targetdetection task. Memory \& Cognition, 5, 371-376.

STERNBERG, S. (1966). High speed scanning in memory. Science, 153, 652-654

(Manuscript received July 20, 1987; revision accepted for publication May 18, 1989.) 